\title{
Anxiety and arousal: A study of two-flash fusion and skin conductance'
}

RICHARD J. ROSE

UNIVERSITY OF ILLINOIS

The relationship of clinical anxiety level to two indicants of arousal was evaluated in 40 drug-free patients. A rangecorrected index of skin conductance and the threshold for two-flash fusion were used; both measures showed significant correlations with anxiety level.

Neuronal recovery cycles for visual (Lindsley, 1961), auditory (Steriade \& Demetrescu, 1962), and somaesthetic (Schwartz \& Shagass, 1963) stimuli are transiently reduced following brief electrical stimulation of the ascending reticular system. Vaughan \& Costa (1964) have related the recovery cycle of the visual evoked response (VER) to perceptual resolution of paired flashes. Their data demonstrate a close quantitative relationship between recovery function of the VER and percentage of paired flashes subjectively resolved as a function of interstimulus interval (ISI); an evoked response to the second flash begins to appear at the same ISI at which some pairs are subjectively resolved.

Such evidence suggests that the threshold for perceptual fusion of paired flashes may serve as an indicant of arousal level. This hypothesis receives support from two lines of study: two-flash fusion (TFF) thresholds correlate with skin conductance and skin potential (Rose, 1964; Lykken, Rose, Luther, \& Maley, 1966) and within-S comparisons reveal that TFF thresholds are raised by a barbiturate and lowered by a stimulant (Kopell, Noble, \& Silverman, 1965).

Based on considerable evidence that clinical anxiety represents a state of hyper-arousal, this report is a study of TFF thresholds and skin conductance levels in a psychiatric sample assessed for anxiety-reactivity. Method

Subjects. A sample of 40 non-psychotic patients was tested. All Ss were drug-free; most were new referrals to out-patient services. Mean age was $26.8 \mathrm{yr}$. Any case with known organic dysfunction and any case where Visual disturbances were part of the presenting symptomatology was excluded. All patients were administered an MMPI, and their profiles were independently rankordered for "tension proneness" by two clinicians. Each $S$ was also given a 40-item scale of anxietyreactivity developed from the work of Lykken (1957). Lykken's strategy is to assess the degree to which unpleasant experiences of an anxiety-eliciting nature are avoided in favor of equally unpleasant, but nonfrightening alternatives. A pool of 360 such items, split between onerous and frightening content, has been sorted by college Ss on a 10-point scale of unpleasant- ness. From a factor analysis of these data (Lykken, unpublished materials) 80 selected frightening and onerous items were paired according to their means and variances from the sortings on unpleasantness. The resulting scale of 40 paired items was presented in a forced-choice format. With other versions of the same scale Lykken has found high internal consistency and satisfactory retest stability under stable conditions (although there is evidence that the scale is sensitive to "state" as well as "trait" anxiety); evidence of the validity of the scale used here has been obtained by Rose (1964).

Apparatus. Conductance was measured directly by connecting a constant voltage source of $0.4 \mathrm{v}$ in series with $\mathrm{S}$ and a small resistor; the signal across this resistor was fed into a Sanborn recording system. Zinc electrodes, $3 / 8$ in, in diameter, were centered on the middle phalanx of the first and third fingers. The electrolyte was a .05 molar concentration of $\mathrm{ZnSO}_{4}$ in a neutral base. Effective electrode area was held corstant by boring a $3 / 8$ in. hole in surgical tape which was applied over the electrode sites; a corn-pad was centered over each hole, half-filled with electrolyte, and the electrodes applied. With this arrangement apparent skin conductance varied from 0.5 to 14.0 micro-mhos, and current density remained below 6.0 micro-amps $/ \mathrm{cm}^{2}$. A Grass photo-stimulator, set to lowest intensity level, was used to present paired flashes of approximately 10-micro-sec. duration with ISI variable from 15 to $150 \mathrm{msec}$. The light source was mounted in an insulated box behind an edge-lit fixation screen; visual angle of the light source was $6.5^{\circ}$. The experimental room was dark except for a shielded light located behind a partial partition separating $\mathrm{E}$ from $\mathrm{S}$.

Procedure. A 3-min. relaxation period was used to allow $S$ to accommodate to the fixation patch and to provide an estimate of basal conductance level. Threshold for TFF was obtained by the method of constant stimuli. S was presented 50 trials of paired flashes centered about his estimated threshold as determined from preliminary testing; 10 trials were at the ISI of the estimated threshold, and the remaining 40 trials were systematically balanced within $\pm 12 \mathrm{msec}$. of it. In most cases the 50 trials were repeated following a brief rest. Pilot data indicate that TFF thresholds obtained with this procedure show satisfactory retest stability. At the end of TFF measurement $S$ inflated a small rubber balloon until it burst.

Analysis. Skin conductance level recorded during TFF measurement was corrected for individual dif- 
ferences in range of conductance by a method described elsewhere (Rose, 1964; and Lykken et al, 1966 provide rationale and supporting data). Minimum level of conductance recorded during rest and the maximum level induced by the balloon-blow-up are interpreted as crude estimates of the limits of conductance for a given $\mathrm{S}$. Mean conductance level during T FF measurement for each $\mathrm{S}$ was then expressed as a function of his observed range:

$$
\phi_{\mathrm{sc}}=\frac{\text { (mean during } \mathrm{TFF})-(\text { estimated minimum) }}{\text { (estimated maximum) }-(\text { estimated minimum) }}
$$

This correction removes the effects of individual differences in range of conductivity, on the argument that these differences are unrelated to arousal, the underlying variable of interest.

\section{Results and Discussion}

Anxiety level, assessed by the MMPI and by Lykken's scale, showed significant correlations with both indicants of arousal. The correlation of TFF with Lykken's scale was $-.63(p<.01)$; i.e., high anxiety is associated with improved resolution of the paired flashes. Significant relationships were also found between TFF and several indices of anxiety from the MMPI. A rankordering of MMPI profiles for tension-proneness yielded a similar result; inter-judge agreement was high (rho = .84 ), and the pooled ordering showed a correlation of $-.45(p<.01)$ with TFF thresholds. Comparable results were obtained for skin conductance, when rangecorrected by the method given above. Correlation of $\phi_{\text {sc }}$ with Lykken's scale was +.45 , and a rank correlation of $+.34(p<.025)$ was found between $\phi \mathrm{sc}$ and the judges' ordering of tension-proneness. These results provide new empirical support for the clinical hypothesis relating anxiety to an elevated level of internal arousal. The relationship between anxiety and TFF thresholds is particularly striking. Temporal perceptual acuity may offer a simple, yet sensitive index of arousal level, and further work with this measure is clearly warranted.

One cautionary comment is necessary. That neuronal recovery cycles are modulated by reticular arousal seems clear. But TFF, the perceptual analogue of the recovery cycle, may be influenced by several factors unrelated to arousal level. In particular, differences in motivation and compliance may generate some of the variance in reported TFF thresholds. As one check on this possibility, data for Ss with extreme TFF thresholds were compared. Psychometric ogives for Ss with highest and lowest thresholds exhibited only negligible differences in form and slope, and data for every $S$ showed a continuous increase in percentage of resolved flashes for increasing ISI. But this difficulty, and the allied problem of subjective criteria for reporting temporal fusion, can best be circumvented through the use of forced-choice procedures; we have now begun some studies of TFF with this methodology.

\section{References}

Kopell, B. S., Noble, E. P., \& Silverman, J. The effect of thiamylal and methamphetamine on the two-flash fusion threshold. Life Sci., 1965, 4, 2211-2214.

Lindsley, D. B. The reticular activating system and perceptual integration. In D. E. Sheer (Ed.), Electrical stimulation of the brain. Austin, Texas: University of Texas Press, 1961.

Lykken, D. T. A study of anxiety in the sociopathic personality. J. abnorm. soc. Psychol., 1957, 55, 6-10.

Lykken, D. T., Rose, R., Luther, B., \& Maley, M. Correcting psychophysiological measures for individual differences in range. Submitted for publication, 1966.

Rose, R. J. Unpublished Ph.D. thesis, University of Minnesota, 1964.

Schwartz, M., \& Shagass, C. Reticular modification of somatosensory cortical recovery function. EEG clin. Neurophysiol., 1963, 15, 265-269.

Steriade, M., \& Demetrescu, M. Reticular facilitation of responses to acoustic stimuli. EEG clin. Neurophysiol., 1962, 14, 21-36.

Vaughan, H. G., \& Costa, L. D. Application of evoked potential techniques to behavioral investigation. Ann. N.Y. Acad. Sci., $1964,118,71-75$.

\section{Nofe}

1. This study was performed at Hennepin County General Hospital, Minneapolis, while the author held a NIMH Research Fellowship. Thanks are due D. T. Lykken, T. Kitesuk and Z. Stelmachers for their help. 